\title{
Motorized Mobility Scooters: The Use of Training/ Intervention and Technology for Improving Driving Skills in Aging Adults - A Mini-Review
}

\author{
Nima Toosizadeh ${ }^{\mathrm{a}}$ Matthew Bunting ${ }^{\mathrm{b}}$ Carol Howe ${ }^{\mathrm{c}}$ Jane Mohler ${ }^{\mathrm{d}}$ \\ Jonathan Sprinkle ${ }^{b}$ Bijan Najafia, d \\ anterdisciplinary Consortium on Advanced Motion Performance (iCAMP) and Southern Arizona Limb Salvage \\ Alliance (SALSA), Department of Surgery, College of Medicine, ${ }^{b}$ Electrical and Computer Engineering, ${ }^{c}$ Arizona \\ Health Sciences Library, and ${ }^{d}$ Arizona Center on Aging, University of Arizona, Tucson, Ariz., USA
}

\section{Key Words}

Scooter $\cdot$ Driver safety $\cdot$ Aging adults $\cdot$ Training .

Virtual environment $\cdot$ Intervention $\cdot$ Assistive tools

\begin{abstract}
Background: Motorized mobility scooters (MMS) have become the most acceptable powered assistive device for those with impaired mobility, who have sufficient upper body strength and dexterity, and postural stability. Although several benefits have been attributed to MMS usage, there are likewise risks of use, including injuries and even deaths. Objective: The aim of the current review was to summarize results from clinical studies regarding the enhancement of MMS driver safety with a primary focus on improving driving skills/performance using clinical approaches. We addressed three main objectives: (1) to identify and summarize any available evidence (strong, moderate, or weak evidence based on the quality of studies) regarding improved driving skills/performance following training/intervention; (2) to identify types of driving skills/performance that might be improved by training/intervention, and (3) to identify the use of technology in improving MMS performance or training procedure. Methods: Articles were searched for in the following medical and engineering electronic databases: PubMed, Cochrane Library, Web of Science, ClinicalTrials.
\end{abstract}

gov, PsycINFO, CINAHL, ERIC, El Compendix, IEEE Explore, and REHABDATA. Inclusion criteria included: aging adults or those with ambulatory problems, intervention or targeted training, and clinical trial. Outcomes included: MMS skills/ performance. Results: Six articles met the inclusion criteria and are analyzed in this review. Four of the six articles contained training approaches for MMS drivers including skill trainings using real MMS inside and outside (i.e. in the community) and in a 3D virtual environment. The other two studies contain infrastructural assessments (i.e. the minimum space required for safe maneuverability of MMS users) and additional mobility assistance tools to improve maneuverability and to enhance driving performance. Conclusions: Results from the current review showed improved driving skills/performance by training, infrastructural assessments, and incorporating mobility assistance tools. MMS driving skills that can be improved through driver training include: weaving, negotiating with and avoiding pedestrian interference, simultaneous reading of signs and obstacle avoidance in path, level driving, forward and reverse driving, figure 8s, turning in place, crossing left slope, maneuvering down a

The content of this article is solely the responsibility of the authors and does not necessarily represent the official views of the National Institute on Aging or the National Institutes of Health.

\section{KARGER}

E-Mail karger@karger.com

www.karger.com/ger
(C) 2014 S. Karger AG, Basel

0304-324X/14/0604-0357\$39.50/0
Bijan Najafi, $\mathrm{PhD}$

Interdisciplinary Consortium on Advanced Motion Performance (iCAMP)

Department of Surgery, College of Medicine, University of Arizona

1656 E Mabel Street, Tucson, AZ 85724 (USA)

E-Mail bnajafi@surgery.arizona.edu 
2-inch curb, and driving up and down inclines. However, several limitations exist in the available literature regarding evidence of improved driving skills/performance following training/intervention, such as small sample sizes, lack of control groups and statistical analysis.

(c) 2014 S. Karger AG, Basel

\section{Introduction}

The increasing population of older adults is associated with a higher prevalence of ambulatory disabilities which, in turn has led to an increased usage of assistive mobility devices. Among these assistive devices, motorized mobility scooters (MMS) have become the most commonly used powered device (after powered wheelchairs), with over 291,000 users in the United States alone in 2008 [1]. Although more recent data regarding MMS usage is not available, it is believed that the number of users has substantially increased in the last decade. Clinical studies have demonstrated several benefits to using MMS, including a higher frequency of outings, increased independence, enhanced ease in mobility, as well as psychological support in all aspects of quality of life [2-4]. In a systematic review, Auger et al. [5] categorized powered mobility devices as well as MMS benefits into: (1) effectiveness (e.g. body function, participation and activity); (2) social significance (e.g. caregiving and cost), and (3) subjective well-being (e.g. quality of life and satisfaction). Within this review, 19 studies were determined to demonstrate the benefits of using powered mobility devices in all three categories.

Although several benefits have been attributed to MMS usage among the older adult population, their prescription remains controversial. Government regulations and reimbursement policies affect the purchase of MMS, causing many elders to opt for more easily reimbursed wheelchairs, in lieu of MMS, and others to buy them out of pocket. Thus, as customers opt for low-cost MMS, present research efforts in powered mobility devices have been targeted to the development of low-cost MMS, rather than safety enhancement. This is in distinct contrast to the development of sophisticated guidance and safety devices in wheelchair design [6]. In addition to reimbursement issues, there remain significant health and safety issues, including the potential for deconditioning with the exacerbation of underlying chronic conditions [3], and the potential for both operator and pedestrian injuries due to unintended collisions [7].

Aging-related changes place elders at increased operator risk. Impairments may occur in vision, cognition and perception, all of which can contribute to slowed visualspatial attention, diminished reflexive responses and compromised executive functioning [7-10]. To this end, an epidemiological study revealed that in a sample of 200 practicing clinicians, approximately $85 \%$ reported client inability to use powered mobility devices due to lack of motor skills, strength, or visual performance [7]. MMSrelated accidents (most commonly tipping over) occur as a consequence of: limited curb cuts, shared vehicular and pedestrian street and sidewalk space, instability while turning around corners, and excessive downhill speeding [3, 8-10]. Furthermore, in a retrospective cohort study, Zagol and Krasuski [11] observed a detrimental effect of long-term (6 years) MMS usage on cardiovascular performance and insulin resistance, with a resultant increased risk of diabetes prevalence. In a recent review paper, issues related to older adult pedestrian and MMS users were investigated, and the following examples of lack of comprehensive urban planning and road safety policies were identified as leading to a higher risk of pedestrianvehicle crashes: a pedestrian-vehicle separation, uncontrolled crossings, roadway lighting, and widening of footpaths and curbs [1].

Despite the aforementioned safety and health issues, reports indicate that MMS usage among the aging population is increasing significantly, and consequently the number of MMS-related accidents has increased as well [12-14]. In an epidemiological study, 650 powered mobility device-related injuries were reported in the United States, among which $52.8 \%$ were associated with MMS [15]. In another clinical study of 43 elderly MMS users, more than $18 \%$ reported accidents during a 3-month pe$\operatorname{riod}[3]$.

Golf carts also have become another common motorized mobility device that are used not only on golf courts, but also in hospitals, residential retirement communities, beach communities, airports, national parks, college campuses, businesses, prisons, and military bases $[16,17]$. These devices have recently grown in popularity because of their small size, low maintenance, and ease of use; however, new models have become faster, quieter and more powerful. These factors have led to several safety issues, especially for 'older adults' (over 80 years of age) $[16,18,19]$. According to the National Electronic Injury Surveillance System database, over 147,500 golf cart-related injuries occurred from 1990 to 2006 in the United States, with an increase of $~ 130 \%$ during these 17 years [16]. Golf cart accidents have substantially contributed to craniofacial trauma and spinal cord injuries, and subsequent hospitalization, morbid- 
ity, and mortality [19-21]. In a study by Seluga and Ojalvo [22], providing braking only for rear wheels of golf carts was suggested as a reason for instability and rollover.

Overall, evidence shows a growing trend of MMS usage among older adults; however the safety implications of this increasing use have been largely overlooked (of note, the term MMS includes both regular MMS and golf carts throughout this review paper.) As such, the aim of this mini-review was to summarize results from clinical studies and to identify the potential benefit of training/ intervention and technology in enhancing MMS driver safety with a primary focus on improving driving skills/ performance. We specifically addressed three main objectives: (1) to identify and summarize any available evidence (strong, moderate, or weak evidence based on the quality of studies) regarding improved driving skills/performance following training/intervention; (2) to identify types of driving skills/performance that might be improved by training/intervention, and (3) to identify the use of technology in improving MMS performance or training procedure.

\section{Methods}

Initial search terms were compiled and iteratively refined by content experts in the fields of library science, geriatrics, surgery, epidemiology, and biomedical, electrical and computer engineering. Articles were searched for in the following medical and engineering electronic databases: PubMed, Cochrane Library, Web of Science, ClinicalTrials.gov, PsycINFO, CINAHL, ERIC, EI Compendix, IEEE Explore, and REHABDATA. Both controlled vocabulary terms (e.g. $\mathrm{MeSH}$ ) and keywords were used to search the databases for articles related to MMS, safety, and older adults. The search strategy used in PubMed, upon which the other searches were based, was as follows: (scooter* $[\mathrm{tw}]$ OR instrumented vehicle*[tw] OR powered mobility device*[tw] OR wheelchairs[MeSH Terms] OR durable medical equipment[MeSH Terms] OR biomedical technology[MeSH Terms]) AND (collision*[Text Word] OR tipping[Text Word] OR crash*[Text Word] OR safety errors[Text Word] OR Training[Text Word] OR injur*[Text Word] OR accident*[Text Word] OR prevention[Text Word] OR preventive[Text Word] OR preventative[Text Word] OR 'Consumer Product Safety'[Mesh] OR 'Technology Assessment, Biomedical'[Mesh] OR 'Equipment Safety'[Mesh] OR 'prevention and control'[Subheading] OR 'education' [Subheading] OR 'Psychomotor Performance'[Mesh] OR 'Accidents' [Mesh] OR 'PatientEducation as Topic'[Mesh]) AND (elder[tw] ORelders[tw] OR elderly[tw] OR old[tw] OR older[tw] OR aged[tw] OR aging[tw] OR ageing[tw] OR senior[tw] OR seniors[tw] OR Medicare[tw] OR 'Aged'[Mesh] OR 'Health Services for the Aged'[Mesh] OR 'Medicare'[Mesh] OR 'Aging'[Mesh] OR 'Age Factors'[Mesh] OR 'United States Department of Veterans Affairs'[Mesh] OR 'Geriatrics'[Mesh]).

Motorized Mobility Scooter and Driving Safety
The initial search included articles published before September 2013. Duplicates were removed and two independent reviewers performed separate reviews to select only those articles that related to (or partly related to) MMS usage. A third reviewer served as a tie-breaker. Inclusion criteria included: aging adults $(+40)$, or those with ambulatory problems; interventions or targeted training, and clinical trials. Outcomes included: powered mobility device skills/performance. Articles were also included if only a subpopulation of participants was over 40 years of age. The searches were rerun in mid-September, 2013. Additionally, a separate search for 'golf cart*' was performed in each of the databases.

\section{Results}

The initial search resulted in 2,286 articles following the removal of duplicates. Of these, 234 (10\%) were found to be related to the search topic based on title and abstract. A further independent review by the two reviewers resulted in selection of $24 / 234(10 \%)$ articles that met inclusion criteria based on title and abstract (and the entire article if necessary), with no discordance in selection by the independent reviewers. The reasons for excluding 210 articles include: (1) individuals in studies were $<40$ years old and were without ambulatory disability, and (2) mobility devices other than MMS were studied (no MMS user was included in studies). At this point, the search was further defined by specifying only those articles that addressed actual training/interventions and included inclusion criteria based on the entire article, which led to the exclusion of another 18 articles. Six articles were considered to warrant full review, meeting the inclusion criteria, as outlined above [14, 23-27] (fig. 1). When the searches were rerun as previously and when the term 'golf cart*' was added, an additional 269 potential articles were identified as potentially relevant. After screening by two individual reviewers, it was determined that none of the articles met eligibility criteria.

The selected studies summarized here are based on participants, instrumentation, training/intervention, and test/outcome measures (table 1). Among these, four studies $(67 \%)$ contained training approaches for MMS drivers [14, 23-27], one study (16.5\%) involved infrastructural assessment [26], and one study (16.5\%) used mobilityassistive tools to improve driving skills/performance [27]. Among selected studies, only two (33\%) used control groups to demonstrate the benefit of intervention [14, 24 ], and only one study utilized a randomized approach for assigning participants to control or experimental groups [24]. In two articles (33\%), new technologies were introduced for improving driving performance [24, 27]. 
Fig. 1. Process of article selection and exclusion criteria for extracting articles.

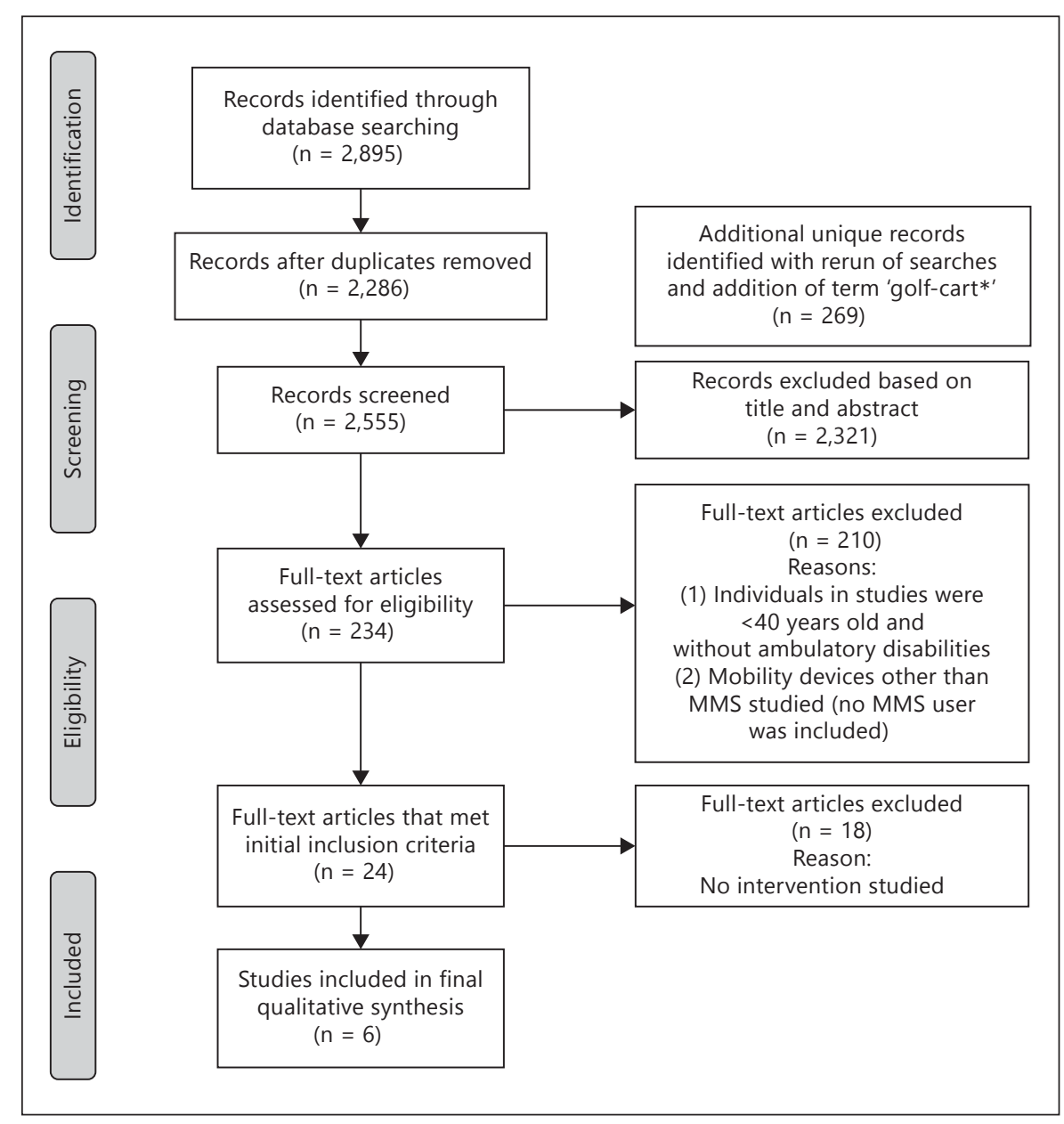

\section{Participants}

Sample sizes of selected studies ranged from 1 to 50 MMS users (table 1), with an age range of 20-97 years. In four studies (67\%), participants were recruited with ambulatory complications related to: stroke, chronic obtrusive pulmonary disorder, multiple sclerosis, musculoskeletal disorder, athetoid cerebral palsy, amputation, central nervous system disorder, cerebral vascular accident, orthopedic injury/deformity, and spinal cord injury [23$26]$. In two other studies (33\%), interventions were performed on individuals without disabilities [14,27]. Inclusion criteria regarding prior experience in driving powered mobility devices differed between studies. Two studies (33\%) excluded adults with prior MMS driving experience $[14,27]$, two studies (33\%) included adults with prior experience of powered mobility driving [25, 26], and two other studies (33\%) did not address the subject's prior powered mobility device driving experience $[23,24]$.

\section{Instrumentation/Technology}

In three articles (50\%) several other types of mobility devices other than MMS were addressed including: powered wheelchair, manual wheelchair, crane, crutch, and walker $[23,25,26]$. Among the three other studies (50\%) that specifically focused on MMS [14, 24, 27], the specific type of MMS (e.g. whether 3- or 4-wheeled) was only mentioned in two $(33 \%)[14,27]$.

Other instrumentation rather than MMS were used in two studies. Jannink et al. [24] used a powered scooter simulation program as a new technology for training MMS drivers. The simulation environment included: two personal computers as simulation server and visualization client, a head-mounted display (e-Magin Visor Z-800) to simulate the driving environment, a $3 \mathrm{D}$ orientation tracker (MT9; Xsens Motion Technology), an electric scooter with customized serial interface, speakers, and a computer display with a mouse. The $3 \mathrm{D}$ virtual environment was designed with the 3D animation software Lumo Scenario, 
Table 1. Categorized articles related to MMS driving interventions based on participants, instrumentation, training/intervention, and test/outcome measures

\begin{tabular}{|c|c|c|c|c|}
\hline Reference & Participants & Instrumentation & Training/intervention & Test/outcome measure \\
\hline Hall et al. (2005) [23] & $\begin{array}{l}\text { Number: } 5 \text { MMS users out of } 12 \\
\text { Age (range): } 84 \text { ( } 73-97) \text { years } \\
\text { Condition: stroke, chronic } \\
\text { obstructive pulmonary disorder, } \\
\text { multiple sclerosis, and } \\
\text { musculoskeletal disorders } \\
\text { Experience: not controlled }\end{array}$ & $\begin{array}{l}\text { Both powered } \\
\text { wheelchair and MMS } \\
\text { Type of MMS: not } \\
\text { specified }\end{array}$ & $\begin{array}{l}\text { Skill: accessing bed, dresser, } \\
\text { and closet, using bathroom, } \\
\text { using doors, using elevator, } \\
\text { parking, ramps, turning left } \\
\text { and right, U-turn, driving } \\
\text { backward, manipulating, } \\
\text { maneuverability, obstacles, } \\
\text { speed selection, and sharing } \\
\text { public space } \\
\text { Duration: } 2 \text { weeks (six } \\
\text { 1-hour sessions) }\end{array}$ & $\begin{array}{l}\text { Power-Mobility Indoor Driving } \\
\text { Assessment (PIDA) } \\
\text { Skills: accessing bed, dresser, and } \\
\text { closet, using bathroom, using } \\
\text { doors, using elevator, parking, } \\
\text { ramps, turning left and right, } \\
\text { U-turn, driving backward, } \\
\text { manipulating, maneuverability, } \\
\text { obstacles, speed selection, and } \\
\text { sharing public space }\end{array}$ \\
\hline Nitz (2008) [14] & $\begin{array}{l}\text { Number: } 10 \text { of out } 50 \text { went } \\
\text { through training } \\
\text { Mean age (range): } 34 \text { (20-66) } \\
\text { years } \\
\text { Condition: healthy } \\
\text { Experience: no experience of MMS } \\
\text { or wheelchair driving }\end{array}$ & $\begin{array}{l}\text { The Shoprider }{ }^{\mathrm{TM}} \text { scoot- } \\
\text { er, } 3 \text {-wheeled, } 90 \mathrm{~cm} \\
\text { long and } 60 \mathrm{~cm} \text { wide, } \\
\text { and maximum speed of } \\
10 \mathrm{~km} / \mathrm{h}\end{array}$ & $\begin{array}{l}\text { Skill: acceleration, reversing, } \\
\text { right and left turn, U-turn, } \\
\text { weave test, zigzag test, avoid } \\
\text { pedestrians, curb cut-out } \\
\text { with and without pedestrian, } \\
\text { read signs above head, read } \\
\text { signs at eye height and avoid } \\
\text { obstacles } \\
\text { Duration: } 3 \text { sessions }\end{array}$ & $\begin{array}{l}\text { Skill: acceleration, reversing, right } \\
\text { and left turn, U-turn, weave test, } \\
\text { zigzag test, avoid pedestrians, } \\
\text { curb cut-out with and without } \\
\text { pedestrian, read signs above head, } \\
\text { read signs at eye height and avoid } \\
\text { obstacles }\end{array}$ \\
\hline Jannink et al. (2008) [24] & $\begin{array}{l}\text { Number: } 10 \text { (5 intervention and } 5 \\
\text { control) } \\
\text { Age (SD): } 61.8 \text { (2.97) years for } \\
\text { intervention and } 58.0 \text { (12.9) years } \\
\text { for control group } \\
\text { Condition: stroke } \\
\text { Experience: not controlled }\end{array}$ & $\begin{array}{l}\text { Type of MMS for actual } \\
\text { tests not specified } \\
\text { Electric scooter } \\
\text { simulation program for } \\
\text { training (3D virtual } \\
\text { environment): head- } \\
\text { mounted display, 3D } \\
\text { orientation tracker, } \\
\text { electrical scooter }\end{array}$ & $\begin{array}{l}\text { Skill: 3D virtual environment } \\
\text { for three levels of complexity: } \\
\text { traffic garden (basic driving } \\
\text { skills), residential area, and } \\
\text { grocery store } \\
\text { Duration: } 30 \text { min twice a } \\
\text { week for } 5 \text { weeks }\end{array}$ & $\begin{array}{l}\text { Functional Evaluation Rating } \\
\text { Scale (FERS) } \\
\text { Skill: starting and stopping at } \\
\text { will/upon request, driving } \\
\text { straight ( } 3.5 \mathrm{~m} \text { ) in open area/ } \\
\text { narrow corridor, passing through } \\
\text { doorways, } 360^{\circ} \text {-turn, } 90^{\circ} \text {-turn, } \\
\text { driving backward, avoiding } \\
\text { people and furniture, driving to } \\
\text { specific location, right and left } \\
\text { turn, planning efficient trip } \\
\text { Subjective experience using } \\
\text { questionnaire }\end{array}$ \\
\hline Koontz et al. (2010) [26] & $\begin{array}{l}\text { Number: } 14 \text { MMS users out of } 223 \\
\text { Mean age (SD): } 46.7 \text { (14.7) } \\
\text { Condition: amputee, central } \\
\text { nervous system disorder, cerebral } \\
\text { vascular accident, orthopedic } \\
\text { injury/deformity, spinal cord injury } \\
\text { Experience: experienced in using } \\
\text { MMS or wheelchair }\end{array}$ & $\begin{array}{l}\text { Mobility devices } \\
\text { including power } \\
\text { wheelchair, manual } \\
\text { wheelchair, and MMS } \\
\text { Type of MMS for actual } \\
\text { tests not specified }\end{array}$ & $\begin{array}{l}\text { Infrastructural intervention: } \\
\text { a mock environment to } \\
\text { determine the minimum } \\
\text { space required for L-turn, } \\
360^{\circ} \text {-turn in place, and } \\
\text { U-turn with and without a } \\
\text { barrier }\end{array}$ & $\begin{array}{l}\text { Outcome measures: minimum } \\
\text { space requirement for L-turn, } \\
360^{\circ} \text {-turn in place, and U-turn } \\
\text { with and without a barrier }\end{array}$ \\
\hline Eck et al. (2012) [27] & $\begin{array}{l}\text { Number: } 38 \\
\text { Age (range): } 67.8(59-86) \text { years } \\
\text { Condition: healthy } \\
\text { Experience: no experience of MMS } \\
\text { driving }\end{array}$ & $\begin{array}{l}\text { The car-like scooter } \\
\text { Trophy } 4 \mathrm{~W}^{\circledR} \\
\text { (Handicare } \mathrm{GmbH}) \text {, } \\
\text { maximum speed of } 15 \\
\mathrm{~km} / \mathrm{h}\end{array}$ & $\begin{array}{l}\text { Mobility assistance system } \\
\text { on MMS: collision avoidance } \\
\text { function, assistance at } \\
\text { bottlenecks, parking } \\
\text { assistance, and navigation } \\
\text { system }\end{array}$ & $\begin{array}{l}\text { Skill: reverse driving, bends, } \\
\text { ascents, parking and bottleneck } \\
\text { Subjective evaluation: based on } \\
\text { personal experience (applica- } \\
\text { tions, strengths, and weaknesses) } \\
\text { of functionalities of the single } \\
\text { mobility assistance components }\end{array}$ \\
\hline
\end{tabular}


and used only for training sessions (not testing the driving performance). Ten participants were randomly assigned to either the experimental group (5 participants) for virtual training or to the control group (5 participants) for regular MMS driver training in 'real world' conditions.

In the most recent study by Eck et al. [27], mobility assistance tools were added to the MMS to enhance driving skills (to achieve collision avoidance, assistance at bottlenecks, parking, and navigation separately) and tested among four groups of healthy older adults (table 1). A small microcontroller (AT90CAN128 from ATMEL) was integrated in the MMS to receive commands from the operator and forward them to MMS control box. Furthermore, two incremental sensors were connected to this microcontroller to measure the vehicle velocity and help the MMS driver estimate severity of incline. A collision avoidance system was integrated using ultrasonic sensors and a laser range finder. With this technology, if there is an obstacle in the driving path of the MMS, the system reduces the velocity and stops the MMS $20 \mathrm{~cm}$ in front of the observed obstacle. Moreover, a new localization system was incorporated in the MMS to determine the user's geographic position and to provide special map attributes such as pedestrian zones, stairs, crosswalks, and sidewalks. In contrast with previous global positioning systems (GPS) that are used for automobile navigation, the new localization system has the advantages of working indoors (and in indoor-like environments), working at slower speeds, and providing MMS driver map data (e.g. route calculation to avoid motorways and highways). To improve the original GPS system, the WLAN Positioning System (WPS) was added to improve the precision of localization and to improve accessibility within buildings.

\section{Training/Intervention}

Several types of training and intervention were used for improving driving skills/performance (table 1). In the two studies that incorporated MMS driving training [23, 24], the duration of training ranged between 2 and 5 weeks; in the other two training studies, the numbers of training sessions (1-3 training sessions) were mentioned without clarifying their durations $[14,25]$. Although several training tasks were used within these studies (a total of $\sim 24$ different training tasks - see table 1 for details), the two basic tasks of 'forward and reverse driving' and 'right and left turning' were common among all of these studies [14, $23,25]$, and in one study [24], training tasks were not indicated. Real MMS were used for training in all studies except one, which used a 3D virtual environment to train MMS users (see Instrumentation/Technology section).
Two studies went beyond training methods for enhancing MMS driving performance. Koontz et al. [26] investigated infrastructural intervention (table 1 ), specifically minimum required space for mobility device users, to improve maneuverability. They indicated an average minimum space requirement (widths) of $93,215,165$, and $214 \mathrm{~cm}$ for L-turn, U-turn with barrier, U-turn without barrier, and $360^{\circ}$-turn, respectively. Eck et al. [27] installed an additional assistance system on the MMS in their study to improve collision avoidance, assist in bottleneck maneuvers, parking, and navigation (see Instrumentation/Technology section).

\section{Test/Outcome Measure}

For each of the MMS training studies, a distinct testing method of driving skills was used, including the following: (1) Power-Mobility Indoor Driving Assessment (PIDA) [23]; (2) Driver Competency Test (DCT) [14]; (3) Functional Evaluation Rating Scale (FERS) [24], and (4) Community Mobility Skills Course (CMSC) [25]. Interestingly, and similar to what we observed from training protocols, 'forward and reverse driving' and 'right and left turning' tasks were shared in common among all these tests; while overall, 27 different assessment tasks were utilized (see table 1 for details). There were differences not only in the types of assessments, but also in the approaches for scoring. In the PIDA and FERS tests the scoring was based on categorical quality of performance (e.g. $1=$ very good, 2 = needs improvement, 3 = tries to perform, and $4=$ is not able to perform); in CMSC the scoring was based on duration (i.e. the required time for finishing each task), completion, safety and task instruction; finally, in DCT scoring was coded with a dichotomous ' 1 = safe' and ' 2 = failure' and failure proportions were calculated for each task among all participants. In contrast to other tests, DCT was used to evaluate the improvement in each task among the group of participants. Moreover, in two studies, subjective self-evaluation (i.e. questionnaires based on application, strengths, weaknesses, driving ability, content, performance, safety, and comfort) assessed MMS driving experience [14, 27].

\section{Observations}

Overall, in all selected studies improvements in driving skills/performance were observed using both training and assistive tools for MMS users. MMS driving skills that were improved with training included: weaving, negotiating with and avoiding pedestrian interference, simultaneous reading of signs and obstacle avoidance in path, level driving, forward and reverse driving, figure $8 \mathrm{~s}$, turning in 
place, crossing left slope, maneuvering down a 2-inch curb, and driving up and down inclines [14, 23-26].

Only two studies used control groups to assess the effect of training on MMS driving skills [14, 24]. Jannink et al. [24] used a simulation program to train MMS users (5 participants for virtual training and 5 participants for regular MMS training in the real world). Overall, they reported improvement in FERS tests in both groups; however, the improvement percentage was more noticeable in the virtual training group (control: 6.9\%; experimental: 7.2\%). No substantial changes in subjective ratings regarding driving abilities, content, performance, safety, and comfort were observed in the two groups. In the other study, Nitz [14] conducted DCT (table 1) on healthy participants; 10 out of 50 participants then undertook the test three separate times as training sessions. The authors' results demonstrated that most tasks (except for weave and zigzag) were mastered by the third assessment (100\% reduction in overall number of failures); however, no comparison between experimental and control group was performed.

In the other two training studies, only one group of participants (no control group) performed training for mobility devices [23, 25]. Hall et al. [23] conducted sessions of training in two groups of participants, with the main objective of determining the effect of training duration on overall driving performance (see table 1 for measurement details). Although they found a significant effect of training duration, only one group of participants (71\% of one group) used MMS for the training/testing, and only post-training driving performances were evaluated. In the other research by Walker et al. [25], an inside mobility skills course (IMSC) was used to relate mobility device skills in a controlled environment to a community mobility skills course (CMSC). In this instance, the IMSC was considered a training method to improve community mobility skills. From a MMS usage viewpoint, this study was limited, as only 1 participant used the MMS as a mobility device. Her results revealed that she performed nine tasks (i.e. all tasks in table 1 except cross slope in right direction, going down a 1.5 -inch curb, and propelling on uneven terrain) faster on the CMSC than the IMSC.

In the final two studies, interventions other than training were used to improve MMS driving performance. Koontz et al. [26] investigated infrastructural intervention (table 1), specifically minimum space required for mobility device users. According to their results, using available guidelines (i.e. Accessibility Guideline for Building and $\mathrm{Fa}$ cilities-ADAAG [28]), 55 and $60 \%$ of the participants would not be able to perform smooth U-turns and L-turns, respectively. Moreover, Eck et al. [27] added mobility assistance tools to the MMS to enhance driving skills among older adults (table 1). The study revealed that the assistance tools were generally positively evaluated; however, they were only able to help MMS users in steering and speed control, but not in complete control of the driving situation.

\section{Discussion}

In our analysis of the available literature, three separate methods for improving MMS driver performance emerged: training, MMS assistance tools, and infrastructural interventions. We deduce that an increase in MMS driving performance may be facilitated by training/interventions. Of note, these findings were concluded from only six clinical studies with several limitations.

\section{Methodological Issues}

In general, the reviewed studies lacked rigorous research methods. Selection criteria were not well described; prior MMS driving experience in two studies $[23,24]$ and age of participants in one study [14] were not controlled, a shortcoming which must be addressed in future research. Among the two studies that considered experimental and control groups for testing outcomes [14, 24], only one utilized a randomization approach for assigning participants to control or experimental groups [23]. Further, due to the limited number of participants, most of the articles involving MMS training ( 3 out of 4 ) were considered to be pilot studies [23-25]. In one study, in which 50 participants were recruited, only $10(20 \%)$ actually underwent the training sessions. Finally, statistical analysis was not performed to compare pre- and post-training alterations in MMS driving performance in any of the reported studies. We were unable to perform statistical analysis on available results because of the limited number of available studies and considerably different methodological approaches involved.

\section{Future Direction: MMS Training}

All studies that used training for improvement of MMS driving skills lacked an adequate number of qualified participants, with a sample size ranging from 1 to 10 participants. Most of the training and testing protocols were copied from powered wheelchair and automobile driving tests, which may have contributed to inconsistency in these protocols. Of note, all MMS driving skills that were determined to be improvable using training sessions (see above) should be considered in the standard- 
ized training approach. Another important limitation inherent in the available literature on MMS trainings is related to the type of mobility devices considered. In two studies $[23,25]$, other mobility devices (e.g. wheelchairs, canes, walkers) were also included, which detracted from the reliability of conclusions made about MMS training. Also, the type of MMS used (e.g. 3- or 4-wheeled, and maximum speed of the scooter) are key variables that need to be controlled for in a clinical study; however, this variable was controlled in only two out of six studies [14, 27]. Failing to account for this potentially important confounder could introduce errors in longitudinal and crosssectional comparison of skill improvement results.

\section{Future Directions: Infrastructural Assessment and}

Assistive Tools for MMS

Only two papers in our analysis offered interventions other than MMS user training $[26,27]$. In the work by Eck et al. [27], an increased performance in steering and speed control was reported using MMS assistance tools. Conclusions from this research, however, were based only on subjective evaluations/interviews regarding functionality of the mobility assistance components. In the other study, Koontz et al. [26] evaluated space requirements for mobility devices; however, MMS users comprised the smallest group (7\%, 14 users) in this study. Their results are therefore more applicable across types of wheelchairs. Specific investigation across different types of MMS is required in future research.

\section{Nonclinical Interventions for MMS Usage}

Although articles about advancement of MMS performance without clinical studies were not the primary focus of the current review, a summary of related articles was also discussed here. In a study by Eck et al. [29], a laser range finder detection device was utilized to assist in driver navigation in narrow passages. Moreover, spatial requirements for MMS turning maneuvers (i.e. $180^{\circ}$-turn with and without barrier, $90^{\circ}$-turn, and three-point turning) were assessed for several types of scooters [30, 31], and results showed that available guidelines could not meet the minimum space requirements even for the smallest MMS size.

More recently, Hirai et al. [32] developed an intelligent robot MMS equipped with sensors, electronic devices and intelligent navigation functions that could autonomously navigate in public areas to minimize the possibility of collision with pedestrian and bicycles. To measure velocity and angular velocity, two encoders (Nidec Copal Co., RE30E-360-213-1) were installed into the wheels. These sensors were combined with an optical fiber gyro (Tamaga- wa Seiki Co., Ltd., TAG0007) to increase the accuracy of measurement and reduce errors due to road slippage. For the purpose of landmark scanning, a laser range scanner (Hokuyo Automatic Co., Ltd.) was added to a platform. The combination of these sensors and software framework (CARTIS TypeR) provided the following navigation functions for the intelligent MMS: (1) robust localization of personal mobility robot in a real environment in which ordinary pedestrians and bicycles are moving; (2) the control function preventing the robot from moving to obstacles on the path, and (3) path following as moving function considering the results of localization and obstacle avoidance. Although these innovative approaches have not been tested in elder drivers, they are potentially important in enhancing MMS driver safety.

\section{Summary and Limitations}

As our population ages and increases in size and lifespan, elders living with mobility impairments will require strategies to support their 'aging in place' in the home and community. MMS and golf carts are posed to play an increasing role in supporting their independence and quality of life; however as in all medical interventions, these devices carry their own risks. Among 234 articles considered in the initial search, most were excluded due to their focus on powered wheelchairs, rather than MMS. Results from this review demonstrate that although MMS have been used for decades by older adults, and despite their increasing use, only a few studies address methods for improving MMS driving skills/performance. The results from this mini-review provide knowledge regarding advantages and limitations of existing training/intervention methods.

Future MMS research should adapt and build upon the electric wheelchair evidence base of sophisticated guidance and safety devices, and driving skill tests and trainings, with the goal of supporting the independence of older adults, and keeping them and those that share the road safe. This should be helpful for future researchers in addressing the existing gap in terms of improving clinical trainings/interventions for MMS users, with the ultimate goal of enhancing independence and safety for MMS drivers.

\section{Acknowledgements}

This study was partially supported by an STTR-Phase II Grant (Award No. 2R42AG032748) from the National Institute on Aging, and the Arizona Center on Aging. We thank Dr. Alon Efrat and Dr. Gurtej Grewal for supporting the literature search and study selection. 


\section{References}

1 Jancey J, Cooper L, Howat P, Meuleners L, Sleet D, Baldwin G: Pedestrian and motorised mobility scooter safety of older people. Traffic Inj Prev 2013;14:647-653.

-2 Auger C, Demers L, Gélinas I, Miller WC, Jutai JW, Noreau L: Life-space mobility of middle-aged and older adults at various stages of usage of power mobility devices. Arch Phys Med Rehabil 2010;91:765-773.

$\checkmark 3$ Hoenig H, Pieper C, Branch LG, Cohen HJ: Effect of motorized scooters on physical performance and mobility: a randomized clinical trial. Arch Phys Med Rehabil 2007;88:279286.

4 Löfquist C, Pettersson C, Iwarsson S, Brandt A: Mobility and mobility-related participation outcomes of powered wheelchair and scooter interventions after 4-months and 1-year use. Disabil Rehabil Assist Technol 2012;7:211-218.

5 Auger C, Demers L, Gélinas I, Jutai J, Fuhrer MJ, DeRuyter F: Powered mobility for middle-aged and older adults: systematic review of outcomes and appraisal of published evidence. Am J Phys Med Rehabil 2008;87:666680.

6 Global Industry Analysts IWpam: A global strategic business report. http://www. strategyrcom/MCP-3368asp.

$>7$ Letts L, Dawson D, Bretholz I, KaisermanGoldenstein E, Gleason J, McLellan E, Norton L, Roth C: Reliability and validity of the power-mobility community driving assessment. Assist Technol 2007;19:154-163.

$>8$ Baird S, Hill L, Rybar J, Concha-Garcia S, Coimbra R, Patrick K: Age-related driving disorders: screening in hospitals and outpatients settings. Geriatr Gerontol Int 2010;10:288294.

$>9$ Anstey KJ, Wood J, Lord S, Walker JG: Cognitive, sensory and physical factors enabling driving safety in older adults. Clin Psychol Rev 2005;25:45-65.
10 Perryman K, Fitten L: Effects of normal aging on the performance of motor-vehicle operational skills. J Geriatr Psychiatry Neurol 1996; 9:136.

11 Zagol BW, Krasuski RA: Effect of motorized scooters on quality of life and cardiovascular risk. Am J Cardiol 2010;105:672-676.

12 Wells JJ, Wells MJ: Electronic scooters: sweet tooth for danger? J Trauma Acute Care Surg 2011;71:265-266.

13 May E, Garrett R, Ballantyne A: Being mobile: electric mobility scooters and their use by older people. Ageing Soc 2010;30:1219-1237.

14 Nitz JC: Evidence from a cohort of able bod ied adults to support the need for driver training for motorized scooters before community participation. Patient Educ Counsel 2008;70: 276-280.

15 Kirby RL, Ackroyd-Stolarz SA: Wheelchair safety - adverse reports to the United States Food and Drug Administration. Am J Phys Med Rehabil 1995;74:308-312.

16 Watson DS, Mehan TJ, Smith GA, McKenzie LB: Golf cart-related injuries in the US. Am J Prev Med 2008;35:55-59.

$\checkmark 17$ Passaro KT, Cole TB, Morris PD, Matthews D, MacKenzie WR: Golf cart-related injuries in a North Carolina island community, 19924. Inj Prev 1996;2:124-125.

18 McGwin G Jr, Zoghby JT, Griffin R, Rue LW III: Incidence of golf cart-related injury in the United States. J Trauma Acute Care Surg 2008;64:1562-1566.

19 Miller BL, Waller JL, McKinnon BJ: Craniofacial injuries due to golf cart trauma. Otolaryngol Head Neck Surg 2011;144:883-887.

20 Kelly EG: Major injuries occurring during use of a golf cart. Commentary. Orthopedics 1996; 19:519-523.

21 White LC, McKinnon BJ, Hughes CA: Etiologies of pediatric craniofacial injuries: a comparison of injuries involving all-terrain vehicles and golf carts. Int J Pediatr Otorhinolaryngol 2013;77:414-417.

$>22$ Seluga KJ, Ojalvo IU: Braking hazards of golf cars and low speed vehicles. Accid Anal Prev 2006;38:1151-1156.
23 Hall K, Partnoy J, Tenenbaum S, Dawson DR: Power mobility driving training for seniors: a pilot study. Assist Technol 2005;17:47-56.

24 Jannink MJ, Erren-Wolters CV, de Kort AC, van der Kooij $\mathrm{H}$ : An electric scooter simulation program for training the driving skills of stroke patients with mobility problems: a pilot study. Cyberpsychol Behav 2008;11:751-754.

25 Walker KA, Morgan KA, Morris CL, DeGroot KK, Hollingsworth HH, Gray DB: Development of a community mobility skills course for people who use mobility devices. Am J Occup Ther 2010;64:547-554.

26 Koontz AM, Brindle ED, Kankipati P, Feathers D, Cooper RA: Design features that affect the maneuverability of wheelchairs and scooters. Arch Phys Med Rehabil 2010;91:759-764.

-27 Eck D, Schilling K, Abdul-Majeed A, Thielecke J, Richter P, Boronat JG, Schens I, Thomas B, Williger B, Lang FR: Mobility assistance for older people. Appl Bionics Biomech 2012;9:69-83.

28 Design DoJAsfa: Code of Federal Regulation, 1994, pp 490-580.

29 Eck D, Heim T, Hess R, Schilling K: A narrow passage assistance functions on a mobility scooter for elderly people: 7th German Conference on Robotics. Proceedings of ROBOTIK. Frankfurt, VDE, 2012, pp 1-6.

30 Dutta T, King EC, Holliday PJ, Gorski SM, Fernie GR: Design of built environments to accommodate mobility scooter users: part I. Disabil Rehabil Assist Technol 2011;6:67-76.

31 King EC, Dutta T, Gorski SM, Holliday PJ, Fernie GR: Design of built environments to accommodate mobility scooter users: part II. Disabil Rehabil Assist Technol 2011;6:432439.

32 Hirai M, Tomizawa T, Muramatsu S, Sato M, Kudoh S, Suehiro T: Development of an intelligent mobility scooter. International IEEE Conference on Mechatronics and Automation (ICMA), 2012, pp 46-52. 